\title{
Seroma Production After Breast Cancer Surgery has a Pro-Inflammatory Component
}

\author{
Pal B. Szecsi ${ }^{*}, 1, J^{2}$ acob Larsen ${ }^{2}$, John Hørby ${ }^{3}$ and Christen K. Axelsson ${ }^{3}$ \\ ${ }^{I}$ Department of Clinical Biochemistry, Gentofte Hospital, University of Copenhagen, Denmark \\ ${ }^{2}$ Department of Clinical Biochemistry, Ncestved Hospital, University of Copenhagen, Denmark \\ ${ }^{3}$ Department of Breast Surgery, Herlev Hospital, University of Copenhagen, Denmark
}

\begin{abstract}
Seroma formation is the most prevalent postoperative sequela after breast cancer surgery. A total of 263 aspirations of seroma fluid in 42 patients were performed after mastectomy; cytokines were measured in 148 cases. The concentration of interleukin-1 $\beta$ (IL-1), interleukin-6 (IL-6), interleukin-8 (IL-8), interleukin-10 (IL-10), interleukin-12p70 (IL-12) and tumor necrosis factor $\alpha$ (TNF) were measured. The patients underwent 9.0 seroma aspirations on average (range 1-17) during an average of 30.7 days (range 7-72). The average cumulative seroma volume was $2056.1 \mathrm{~mL}$ (range 50-5130). In all samples, the maximal average concentrations of IL-6 (mean $10717 \mathrm{pg} / \mathrm{mL}$, range 136-100000) and IL-8 (mean $7221 \mathrm{pg} / \mathrm{mL}$, range 102-79828) were 55-200-fold above the serum/plasma levels of asymptomatic adults. In contrast, we observed levels similar to normal serum/plasma levels for IL-1 (mean $62.8 \mathrm{pg} / \mathrm{mL}$, range 0-1226), IL-10 (mean $29.8 \mathrm{pg} / \mathrm{mL}$, range 3.6-359), and lower-than-normal serum/plasma levels of TNF (mean $3.4 \mathrm{pg} / \mathrm{mL}$, range 0-31.7) and IL-12 (mean $0.5 \mathrm{pg} / \mathrm{mL}$, range 0-11.8). Patients with clinical infection had generally significant higher maximal IL-6 $(\mathrm{p}=0.004)$ and IL-8 (0.019) than patients without clinical infection. However, most patients had no bacterial infection. None of the cytokines were associated with cumulative seroma volume, duration of seroma production or number of seroma aspirations. Seroma formation after mastectomy has a pro-inflammatory component, as indicated by the high levels of interleukin-6 and interleukin-8. However, these levels do not predict the course of seroma production.
\end{abstract}

Keywords: Breast cancer, cytokines, mastectomy, seroma.

\section{INTRODUCTION}

Seroma, an accumulation of fluid, can infrequently occur after any surgical procedure and is the most prevalent postoperative sequela after breast surgery, with an incidence of $10 \%$ to $85 \%$, leading to significant morbidity and discomfort and possibly delaying adjuvant therapy [1]. Different causes of seroma have been proposed, such as the disruption of lymphatic drainage with fibrinolysis, or the surgical technique, especially the use of electrocautery versus knife dissection [2,3]. Several interventions have been attempted, including the use of tranexamic acid, bovine thrombin application, fibrin glue, avoiding drainage, postoperative arm activity and altering the surgical technique [4]. The origin of seroma remains unclear and no generally accepted preventive or curative method exists [1]. Identification of the causal mechanisms of seroma formation could guide evidence-based treatment. As the name indicates, seroma has traditionally been looked upon as an accumulation of lymph or serum, as repeated recently [5]. Watt-Boolsen et al. concluded that seroma formation was a result of an inflammatory process determined by the cell type and proteins in seroma fluid [6], and this has been confirmed recently [7]. In wound repair, various cells release cytokines, chemokines, and growth factors, which all have the potential to promote seroma formation [8]. Based on the

*Address correspondence to this author at the Department of Clinical Biochemistry, Gentofte Hospital, University of Copenhagen, Denmark; Tel: +46-46-173655; Fax: +46-46-130064; E-mail: pal.szecsi@med.lu.se notion that an inflammatory process contributes to seroma formation, in this paper, we evaluate the cytokine profile in seroma fluid after surgery for primary breast carcinoma. Furthermore, the study investigates whether the cytokine concentration reflects the likelihood of seroma development.

\section{MATERIAL AND METHODS}

\section{Study Group and Surgical Technique}

Between March and May 2007, patients who developed seroma after surgery for primary breast cancer were investigated. Mastectomy or wide local excision was performed with diathermy and sharp dissection in the axilla. The axillary dissection consisted of sentinel lymph node biopsy or axillary clearance of level I or II or both. All patients had a single closed suction drain inserted through the medial end of the incision. The drain was removed when the daily volume was below $100 \mathrm{ml}$ or after a maximum of five days. In case of seroma production, the patients were received in the out-patient clinic and were aspirated by specially trained nurses until the seroma volume was estimated to be below $50 \mathrm{ml}$. The wound was evaluated for infection and necrosis at every visit. The amount of drainage fluid, seroma volume, number of punctures and the presence of any complication was recorded. Wound infection was defined as redness with or without purulent seroma fluid. In case of symptoms of clinical infection, a culture for bacteria was performed. 


\section{Ethics}

The study was performed in accordance with the Helsinki Declaration, and was approved by The Committees on Biomedical Research Ethics of the Capital Region of Denmark (H-D-2007-0006) and the Danish Data Protection Agency. All participants provided informed written consent.

\section{Cytokine Measurement}

The seroma aspirate was kept at $5^{\circ} \mathrm{C}$ until the end of the day of aspiration. Aliquots were stored at $-80^{\circ} \mathrm{C}$ until analysis in batch. The cytokines interleukin-1 $\beta$ (IL-1), interleukin-6 (IL-6), interleukin-8 (IL-8), interleukin-10 (IL10), interleukin-12p70 (IL-12) and tumor necrosis factor $\alpha$ (TNF) were quantified by multiplex microsphere beads \#551811 (BD Biosciences, San Jose, CA, USA) according to the manufacturer's instructions with minor modifications. More than 300 of each bead type were analyzed on a FACSCanto II flow cytometer (BD) at a low flow rate. Data were transformed to FCS2 format and analyzed with FCAP Array V1.0 software (Soft Flow, Pecs, Hungary) using the median fluorescence parameter 2 (FL2). The assay is traceable to NIST/WHO standards $86 / 680$ (IL-1, factor 0.78), 89/548 (IL-6, factor 0.96), 89/520 (IL-8, factor 1.26), and $92 / 513$ (IL-10, factor 1.91), 95/544 (IL-12, factor 1.28) and $87 / 650$ (TNF, factor 0.90 ). The limit of detection is 7.2 $\mathrm{pg} / \mathrm{mL}$ (IL-1), $2.5 \mathrm{pg} / \mathrm{mL}$ (IL-6), $3.6 \mathrm{pg} / \mathrm{mL}$ (IL-8), 3.3 $\mathrm{pg} / \mathrm{mL}$ (IL-10), $1.9 \mathrm{pg} / \mathrm{mL}$ (IL-12) and $3.7 \mathrm{pg} / \mathrm{mL}$ (TNF).

\section{Statistical Analysis}

Groups were compared using a one-way analysis of variance (ANOVA). Levene's test for homogeneity of variance and post-hoc analyses with Dunnett's C or GamesHowell, assuming unequal variances and group sizes, were used to investigate the nature of any differences. Dichotomous logistic regression models were performed to analyze the duration of seroma production ( $<30$ days, $>=30$ days), cumulative seroma volume $(<750 \mathrm{ml},>=750 \mathrm{ml})$, and number of seroma punctuations ( $<7$ times, $>=7$ times), respectively, as the dependent variables, and with maximal normalized transformed values of IL-1 (1/x), IL-6 (ln), IL-8 (ln), IL-10(ln), IL-12 (sqrt), TNF (ln), as well as gender, BMI, surgical procedure, and infection (yes/no) as the independent variables. Associations were expressed as odds ratios with $95 \%$ confidence intervals. In multivariate analysis, only the variables found to be significant in the univariate analysis were used. A value of $p<0.05$ was considered to be statistically significant. Data analyses were performed using the Statistical Products and Service Solutions package (SPSS Inc., Chicago, IL, USA) for Windows (release 15.0).

\section{RESULTS}

The details of the 42 patients with seroma formation are presented in Table 1. A total of 263 seroma aspirations were performed; cytokines were measured in 148 cases. The patients underwent 9.0 seroma aspirations on average (range 1-17) during an average of 30.7 days (range 7-72). The average cumulative seroma volume was $2056.1 \mathrm{~mL}$ (range 50-5130). In all samples, the maximal average concentrations of IL-6 (mean $10717 \mathrm{pg} / \mathrm{mL}$, range 136100000) and IL-8 (mean $7221 \mathrm{pg} / \mathrm{mL}$, range 102-79828) were 55-200-fold above the serum/plasma levels of asymptomatic adults [9]. In contrast, we observed levels similar to normal serum/plasma levels for IL-1 (mean 62.8 $\mathrm{pg} / \mathrm{mL}$, range 0-1226), IL-10 (mean $29.8 \mathrm{pg} / \mathrm{mL}$, range 3.6359), and lower-than-normal serum/plasma levels of TNF (mean $3.4 \mathrm{pg} / \mathrm{mL}$, range 0-31.7) and IL-12 (mean $0.5 \mathrm{pg} / \mathrm{mL}$, range $0-11.8$ ). The maximal concentrations of IL-6 and IL-8 did correlate (2-tailed Spearman's rho $=0.838, \mathrm{p}<0.0001$ ), but not with any of the other cytokines. None of the normalized transformed variables for the cytokines were associated with cumulative seroma volume $(\mathrm{p}=0.122-0.643)$, duration of seroma production $(\mathrm{p}=0.138-0.690)$ or number of seroma aspirations $(\mathrm{p}=0.068-0.618)$.

Only IL-8 showed statistically significant associations $(p=0.009)$ with seroma formation in a model with all the cytokines, but this was not the case in a solitary model $(p=0.555)$. None of the registered variables (Table 1) could predict the course of seroma production. A tendency of correlation between lower IL-6 and IL-8 values and a longer duration of seroma production was observed (Fig. 1); however, some patients abruptly stopped producing more fluid in spite of very high levels a few days previously. Patients with clinical infection had generally significant higher maximal IL-6 ( $p=0.004)$ and IL-8 (0.019) than patients without clinical infection (Fig. 2). Patients with cumulative seroma production $>=750 \mathrm{~mL}$ had significant higher IL-6 $(\mathrm{p}=0.001)$ and IL-8 $(\mathrm{p}=0.0001)$ in patients with than without clinical infection. These differences were not present in patients with low seroma production. Patients with $>=7$ seroma aspiration had significant higher Il-6 $(\mathrm{p}=$ $0.003)$ and $\mathrm{Il}-8(\mathrm{p}=0.004)$ in patients with than without clinical infection, whereas only IL-8 were higher in patients with $<7$ seroma aspiration $(\mathrm{p}=0.024)$. Similarly, patients with longer seroma duration than 30 days had significant higher Il-6 $(\mathrm{p}=0.002)$ and Il-8 $(\mathrm{p}=0.024)$ in patients with than without clinical infection, whereas only IL-8 were higher in patients with $<30$ days seroma duration $(\mathrm{p}=$ 0.036). Interestingly, in the 13 patients with signs of clinical infection, no growth was observed in six of the nine cases were bacterial culture were performed (Table 1). Three cases all revealed Staphylococcus aureus growth in spare to abundant amount.

\section{DISCUSSION}

Most breast cancer patients develop low-volume seroma after surgery; often lasting many weeks [10]. In our group of patients that required at least one aspiration, 21 patients $(50 \%)$ produced $>=750 \mathrm{~mL}, 16$ patients $(38.1 \%)$ underwent $>=7$ aspirations and 17 patients $(40.5 \%)$ had a prolonged duration of $>=30$ days.

The previous notion that seroma after breast surgery is derived from lymph is debatable. Watt-Boolsen et al. investigated drainage fluid during the first 3 days after radical mastectomy in 19 women that developed seroma and in eight women that did not [6]. They found a significant higher concentration of granulocytes than lymphocytes in women with seroma as well as a significant higher concentration of lymphocytes than granulocytes in women without seroma. On the other hand, did Montalto et al. report a preferential lymphocyte percentage (58-94\%) compared to 
Table 1. Demographic Details of Mastectomized Patients and with Maximal Cytokine Concentrations in Seroma Fluid

\begin{tabular}{|c|c|c|c|c|c|c|c|c|c|c|c|c|c|c|c|c|}
\hline ID & $\operatorname{Sex}$ & Age & BMI & Surgery & $\begin{array}{c}\text { Surgery } \\
\text { Duration } \\
\text { (Min) }\end{array}$ & $\begin{array}{c}\text { Dranage } \\
\text { Duration } \\
\text { (Days) }\end{array}$ & $\begin{array}{c}\text { Clinical } \\
\text { Infection }\end{array}$ & $\begin{array}{c}\begin{array}{c}\text { Number } \\
\text { of } \\
\text { Aspitations }\end{array} \\
\end{array}$ & $\begin{array}{c}\text { Cumulative } \\
\text { Volume } \\
\text { (mL) }\end{array}$ & $\begin{array}{c}\text { Seroma } \\
\text { Duration } \\
\text { (Days) }\end{array}$ & $\begin{array}{c}\text { IL-1ß } \\
(\mathrm{pg} / \mathrm{mL}) \\
\text { Max }\end{array}$ & $\begin{array}{c}\text { IL-6 } \\
(\mathrm{pg} / \mathrm{mL}) \\
\text { Max }\end{array}$ & $\begin{array}{c}\mathrm{IL-8} \\
(\mathrm{pg} / \mathrm{mL}) \\
\mathrm{Max}\end{array}$ & $\begin{array}{c}\text { IL-10 } \\
(\mathrm{pg} / \mathrm{mL}) \\
\text { Max }\end{array}$ & $\begin{array}{c}\mathrm{IL}-12 \\
(\mathrm{pg} / \mathrm{mL}) \\
\text { Max }\end{array}$ & $\begin{array}{c}\text { TNF } \alpha \\
(p g / m L) \\
\text { Max }\end{array}$ \\
\hline ALA & $\mathrm{F}$ & 76 & 18.6 & $\mathrm{RM}$ & 92 & 3 & $\mathrm{Yes}^{0}$ & 5 & 1020 & 30 & 27.8 & 50,000 & 8,556 & 34.3 & 0.0 & 0.0 \\
\hline ALJS & $\mathrm{F}$ & 66 & 18.0 & PM & 75 & 4 & No & 4 & 495 & 23 & 136.6 & 34,856 & 8,884 & 30.2 & 0.0 & 12.4 \\
\hline $\begin{array}{c}\mathrm{AME} \\
\mathrm{F}\end{array}$ & $\mathrm{F}$ & 82 & 29.7 & $\mathrm{RM}$ & 130 & 4 & No & 14 & 5130 & 68 & 3.9 & 1,999 & 1,196 & 17.1 & 1.5 & 1.7 \\
\hline ASD & $\mathrm{F}$ & 73 & 26.3 & $\mathrm{RM}$ & 207 & 0 & No & 2 & 360 & 19 & 1.1 & 6,318 & 2,752 & 16.4 & 0.0 & 0.0 \\
\hline BBJ & $\mathrm{F}$ & 51 & 28.3 & $\mathrm{RM}$ & 120 & 4 & Yes & 8 & 780 & 30 & 5.0 & 2,118 & 4,291 & 36.4 & 1.7 & 1.5 \\
\hline BIDN & $\mathrm{F}$ & 69 & 29.4 & PM & 165 & 3 & No & 6 & 1020 & 38 & 0.0 & 136 & 171 & 4.5 & 0.0 & 2.0 \\
\hline $\mathrm{BJ}$ & $\mathrm{F}$ & 70 & 24.5 & $\mathrm{RM}$ & 160 & 1 & No & 6 & 860 & 22 & 0.0 & 1,114 & 717 & 9.9 & 0.0 & 0.0 \\
\hline BS & $\mathrm{F}$ & 76 & 25.8 & PM & 77 & 4 & No & 8 & 780 & 72 & 3.4 & 667 & 529 & 6.4 & 3.3 & 2.3 \\
\hline DV & $\mathrm{F}$ & 48 & 25.0 & $\mathrm{RM}$ & 135 & 4 & $\mathrm{Yes}^{0}$ & 13 & 2845 & 62 & 1.7 & 2,590 & 1,515 & 17.5 & 0.0 & 1.3 \\
\hline DVJ & $\mathrm{F}$ & 49 & 28.4 & PM & 144 & 3 & No & 2 & 60 & 13 & 0.0 & 802 & 171 & 3.6 & 0.0 & 0.0 \\
\hline DW & $\mathrm{F}$ & 62 & 24.7 & PM & 80 & 2 & No & 5 & 760 & 46 & 2.2 & 1,283 & 1,138 & 21.2 & 0.0 & 1.9 \\
\hline EA & $\mathrm{F}$ & 70 & 24.6 & PM & 77 & 0 & No & 1 & 60 & 11 & 0.0 & 1,144 & 102 & 9.3 & 0.0 & 1.1 \\
\hline EG & $\mathrm{F}$ & 45 & 23.4 & MO & 61 & 0 & $\mathrm{No}^{\mathrm{a}{ }^{*}}$ & 2 & 250 & 26 & 15.0 & 29,717 & 7,158 & 31.0 & 0.0 & 10.5 \\
\hline EHB & $\mathrm{F}$ & 89 & 24.3 & $\mathrm{MO}$ & 85 & 1 & $\mathrm{Yes}^{0}$ & 2 & 75 & 22 & 0.0 & 754 & 276 & 5.0 & 0.0 & 0.0 \\
\hline EMJ & $\mathrm{F}$ & 68 & 25.1 & $\mathrm{RM}$ & 187 & 3 & No & 1 & 50 & 7 & 26.4 & 7,805 & 2,060 & 23.7 & 0.0 & 13.1 \\
\hline ES & $\mathrm{F}$ & 64 & 26.9 & PM & 82 & 2 & $\mathrm{No}^{0}$ & 10 & 1070 & 42 & 1.2 & 5,976 & 610 & 14.9 & 0.0 & 12.1 \\
\hline GML & $\mathrm{F}$ & 50 & 26.3 & $\mathrm{RM}$ & 142 & 1 & $\mathrm{Yes}^{0}$ & 3 & 180 & 16 & 3.2 & 4,244 & 3,098 & 18.4 & 0.0 & 0.0 \\
\hline HLU & $\mathrm{F}$ & 80 & 26.8 & PM & 79 & 3 & No & 1 & 50 & 11 & 7.9 & 2,175 & 1,923 & 20.2 & 0.0 & 2.2 \\
\hline HME & $\mathrm{F}$ & 70 & 21.3 & PM & 140 & 2 & No & 17 & 2425 & 50 & 2.4 & 187 & 419 & 7.3 & 0.0 & 2.0 \\
\hline IBL & $\mathrm{F}$ & 64 & 21.0 & $\mathrm{RM}$ & 123 & 4 & No & 8 & 930 & 25 & 2.7 & 2,776 & 2,262 & 20.3 & 0.0 & 1.6 \\
\hline $\mathrm{IL}$ & $\mathrm{F}$ & 72 & 22.5 & PM & 147 & 2 & No & 2 & 120 & 25 & 1.3 & 1,680 & 224 & 5.4 & 0.0 & 1.6 \\
\hline IMB & $\mathrm{F}$ & 85 & 19.5 & $\mathrm{RM}$ & 95 & 5 & $\mathrm{Yes}^{\mathrm{au}^{*}}$ & 5 & 560 & 26 & 727.0 & 21,259 & 72,453 & 358.6 & 2.0 & 15.8 \\
\hline $\mathrm{IN}$ & $\mathrm{F}$ & 76 & 23.9 & $\mathrm{RM}$ & 113 & 5 & Yes & 15 & 3675 & 57 & 38.8 & 5,867 & 13,567 & 29.5 & 1.9 & 1.7 \\
\hline JEA & $\mathrm{M}$ & 65 & 25.9 & PM & 121 & 5 & No & 9 & 2470 & 26 & 0.0 & 329 & 197 & 3.7 & 0.0 & 0.0 \\
\hline JNK & $\mathrm{F}$ & 71 & 20.8 & PM & 90 & 2 & No & 3 & 545 & 43 & 12.0 & 6,202 & 2,805 & 38.9 & 0.0 & 0.0 \\
\hline KBW & $\mathrm{F}$ & 70 & 25.0 & $\mathrm{RM}$ & 180 & 3 & Yes $^{0}$ & 6 & 925 & 25 & 19.7 & 21,070 & 17,182 & 27.0 & 0.0 & 0.0 \\
\hline $\mathrm{KF}$ & $\mathrm{F}$ & 52 & 36.7 & $\mathrm{RM}$ & 137 & 3 & $\mathrm{Yes}^{\mathrm{au}^{* * * *}}$ & 11 & 2350 & 32 & 288.3 & 40,687 & 79,828 & 88.1 & 0.0 & 14.5 \\
\hline KK & $\mathrm{F}$ & 62 & 21.9 & $\mathrm{RM}$ & 87 & 1 & No & 3 & 620 & 17 & 17.7 & 24,232 & 1,389 & 22.0 & 0.0 & 0.0 \\
\hline KPA & $\mathrm{F}$ & 75 & 27.0 & PM & 69 & 0 & $\mathrm{No}^{0}$ & 5 & 430 & 22 & 2.4 & 2,156 & 1,630 & 9.6 & 0.0 & 0.0 \\
\hline LFN & $\mathrm{F}$ & 46 & 21.6 & $\mathrm{RM}$ & 93 & 1 & No & 6 & 540 & 16 & 2.0 & 2,422 & 963 & 7.7 & 0.0 & 0.0 \\
\hline $\mathrm{LÅT}$ & $\mathrm{F}$ & 62 & 25.8 & $\mathrm{RM}$ & 65 & 2 & $\mathrm{No}^{0}$ & 5 & 735 & 22 & 14.7 & 8,320 & 4,304 & 22.4 & 0.0 & 1.2 \\
\hline ML & $\mathrm{F}$ & 47 & 21.9 & $\mathrm{RM}$ & 172 & 4 & No & 4 & 460 & 21 & 1.6 & 1,034 & 143 & 5.9 & 0.0 & 1.1 \\
\hline $\mathrm{MN}$ & $\mathrm{F}$ & 76 & 25.8 & $\mathrm{RM}$ & 107 & 1 & No & 12 & 2005 & 39 & 1.1 & 2,722 & 2,294 & 25.6 & 0.0 & 0.0 \\
\hline MRM & $\mathrm{F}$ & 53 & 18.9 & RM & 84 & 0 & $\mathrm{Yes}^{\mathrm{a} \mathrm{au}^{* *}}$ & 4 & 610 & 9 & $1,226.3$ & 100,000 & 39,244 & 64.1 & 0.0 & 31.7 \\
\hline $\mathrm{RR}$ & $\mathrm{F}$ & 73 & 33.2 & $\mathrm{RM}$ & 172 & 5 & No & 11 & 2490 & 65 & 2.1 & 1,433 & 1,240 & 22.5 & 0.0 & 2.5 \\
\hline SEJ & $\mathrm{F}$ & 54 & 28.6 & $\mathrm{RM}$ & 210 & 4 & No & 12 & 1695 & 33 & 1.2 & 1,097 & 553 & 5.6 & 0.0 & 1.4 \\
\hline UB & $\mathrm{F}$ & 67 & 29.2 & MO & 87 & 1 & No & 8 & 1000 & 55 & 2.9 & 3,701 & 4,375 & 47.7 & 0.0 & 3.0 \\
\hline UBC & $\mathrm{F}$ & 59 & 30.9 & $\mathrm{RM}$ & 144 & 2 & $\mathrm{Yes}^{0}$ & 9 & 2100 & 27 & 33.6 & 30,366 & 5,820 & 32.3 & 0.0 & 1.5 \\
\hline UBW & $\mathrm{F}$ & 66 & 24.0 & RM & 137 & 2 & Yes & 2 & 320 & 15 & 3.4 & 998 & 1,959 & 31.4 & 0.0 & 2.5 \\
\hline ULM & $\mathrm{F}$ & 68 & 24.4 & $\mathrm{RM}$ & 165 & 3 & Yes & 3 & 205 & 29 & 0.0 & 2,137 & 710 & 3.9 & 0.0 & 0.0 \\
\hline $\mathrm{VE}$ & $\mathrm{F}$ & 49 & 22.0 & $\mathrm{RM}$ & 78 & 2 & No & 3 & 380 & 33 & 0.0 & 5,976 & 1,581 & 15.6 & 11.8 & 0.0 \\
\hline $\mathrm{YC}$ & $\mathrm{F}$ & 79 & 26.3 & PM & 94 & 3 & No & 7 & 1300 & 20 & 1.7 & 9,798 & 2,971 & 32.1 & 0.0 & 0.0 \\
\hline
\end{tabular}

$\mathrm{RM}=$ radical mastectomy; $\mathrm{PM}=$ partial mastectomy; $\mathrm{MO}=$ local excision in mammary tissue only; ${ }^{\text {al }}=$ Staphylococcus albus; ${ }^{\text {au }}=$ Staphylococcus aureus; ${ }^{0}=$ no growth; ${ }^{*}=$ sparse growth; ${ }^{* *}=$ moderate growth; ${ }^{* * *}=$ abundant growth. 
$0.1-44 \%$ granulocytes in 11 seroma samples from seven patients, but did not provide the total concentrations [5]. Lymph fluid is characterized by about $95 \%$ dominance of lymphocytes as seen in the thoracic duct $[11,12]$. We did not measure leucocytes in the aspirates, but most were rather clear indicating a low concentration of cells. In a few cases with persisting seroma formation, endoscopic exploration has revealed a nearly serous lined seroma cavity. This is consisting with the immunohistochemical observation of especially CD3 and CD20 lymphocytes, and CD68 macrophages in the postmatectomy seroma beds [13]. In conclusion, it seems unlike that lymph is the source of seroma, however it cannot be ruled out that some lymph spillage occur, especially just after surgery. Also the level of cytokines points away from viewing seroma as lymph. Postnodal lymph in normal rats has very low concentrations of IL-6, which is much lower than the concentration observed here. Rat lymph has similarly low concentrations of IL-1, IL-10 and TNF as we observed in human seroma fluid [14]. Olszewski et al. measured several cytokines in lymph drained from the joints of rheumatoid arthritis patients and from control subjects [15]. They found higher level of e.g. IL-6 and Il-8 in lymph compared to serum in both patients and control, but both at much lower levels than we observed in seroma fluid. Interestingly, the patients generally had higher levels of many cytokines in both lymph and serum, indicating a general inflammatory state. However, if these findings are comparable with seroma formation is questionable, as rheumatoid arthritis is a chronic autoimmune condition.

Purulent infection is characterized by accumulation of leucocytes, which secrete a variety of cytokines. Our patients with symptoms of clinical infection had generally significant higher maximal IL-6 and IL-8 than patients without clinical infection (Fig. 1). However, this did not reflect bacterial growth. Most of the patients with clinical infection had no bacterial growth in culture of seroma fluid, indicting an aseptic inflammation (Table 1). Even though some of the highest maximal levels of cytokines were observed in patients with positive bacterial culture, this was not the obvious in all cases. If clinical infection/inflammation triggers the elevation of cytokines, one might expect an increase in cytokine concentration around the time of infection. This is not pronounced, neither for patients with clinical infection with (KF) nor without (DV) bacterial growth, as exemplified in Fig. (3). It should be noted that the maximal levels of cytokines (IL-6 and IL-8) were about 10 times higher in the patient with abundant Staphylococcus aureus infection, but a great variation among the patients was observed. In addition to leucocyte cytokines may be produced by a variety of different cell types. For example is IL-6 produced by fibroblasts, endothelial smooth muscle cells, chondrocytes, osteoblasts, and keratinocytes. Our results do not provide any information about the source of the cytokines in seroma fluid and they may originate from any of the above mentioned cells.
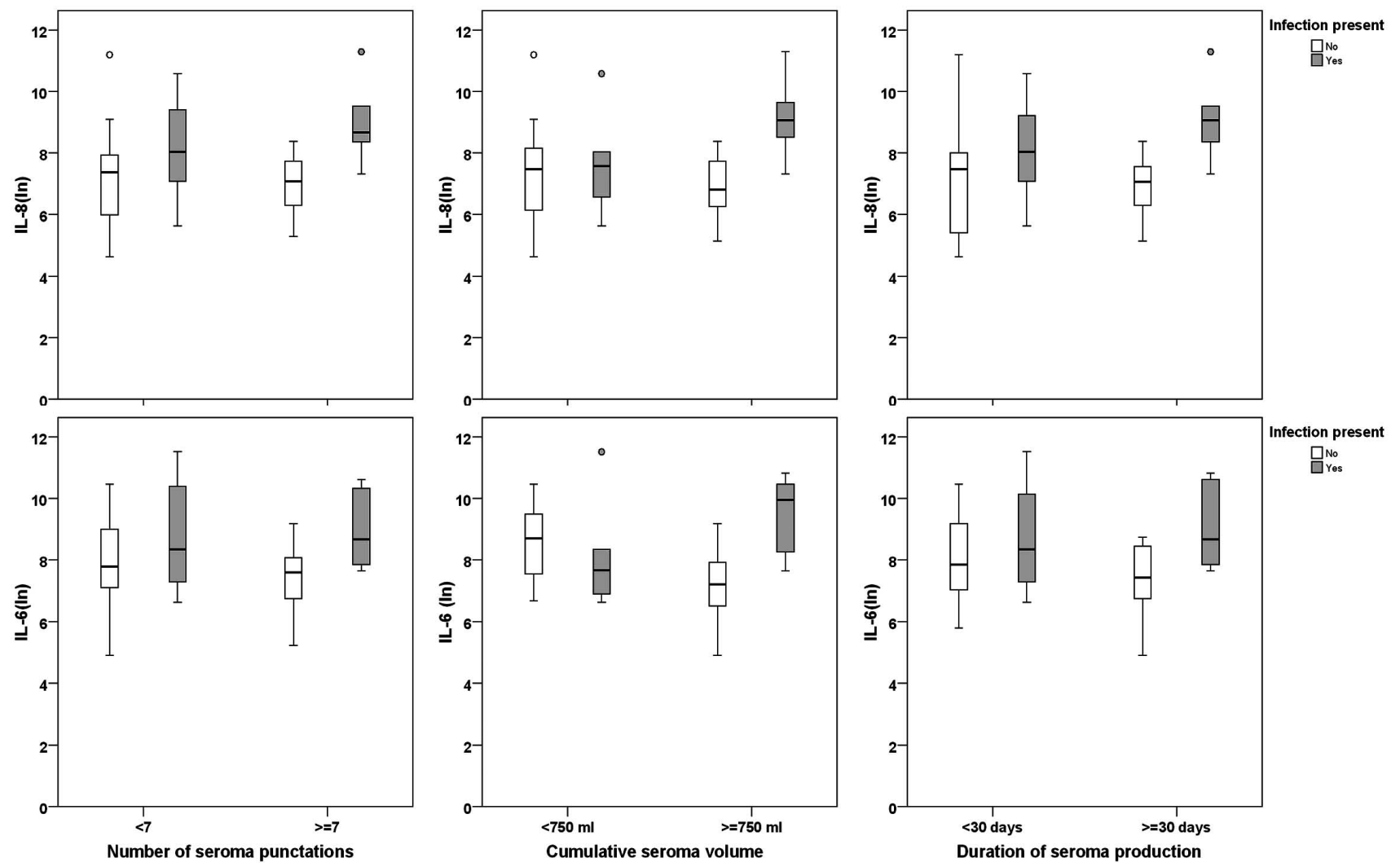

Fig. (1). Maximal interleukin- 6 (IL- 6) and interleukin-8 (IL-8) concentrations in seroma fluid in patients with and without infection after mastectomy. Box plots represent the range of data from the 25th to the 75 th percentile, while the bar in the middle of each box plot represents the median value. The "whiskers" represent highest and lowest values that are not outliers or extreme values. Outliers (1.5 to 3 times the interquartile range) and extreme values (more than 3 times the interquartile range) are represented by circles beyond the whiskers. 


\section{Seroma cytokine concentration}

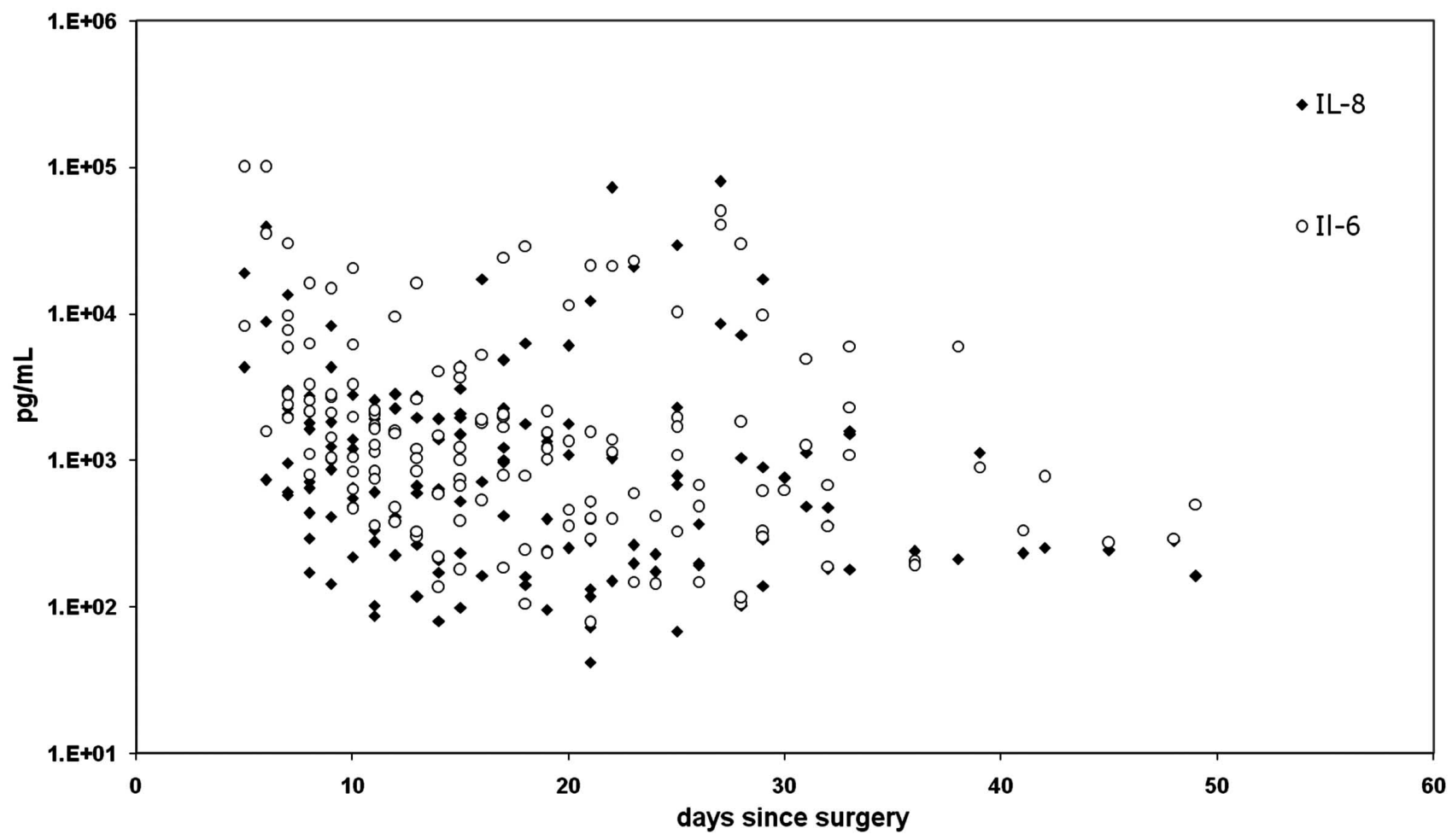

Fig. (2). Interleukin- 6 (IL-6) and interleukin-8 (IL-8) concentrations in 148 of 263 aspirations of seroma fluid in patients in relation to the number of days after mastectomy. A correlation between the two cytokines was found (Spearman's rho=0.38, $\mathrm{p}<0.0001$ ).

Several other factors indicate that seroma production after mastectomy is an inflammatory process. In a rat mastectomy model, Kocdor et al. showed that the immunomodulating 5-fluorouracil was highly effective in preventing seroma formation [16]. In humans, similar high concentrations of IL- 6 as ours were observed in wound fluid up to 3 days after mastectomy [17]. The authors also reported high concentrations of other growth factors especially transforming growth factor beta (TGF- $\beta$ ) and tissue inhibitor of metalloproteinase 1 (TIMP-1). Loo et al. also reported elevated IL- 6 during the first 5 days after mastectomy but at a lower concentration [18]. The authors did not observe elevated levels of TIMP-1. The discrepancy may be due to differences in analytic methods and the lack of standardization. Their findings are in accordance with the cytokine-mediated pro-inflammation that has been reported after a posterior cervical decompression, where high levels of IL-6 and IL-8 were observed [19]. Here, levels of other pro-inflammatory cytokines such as monocyte chemotactic protein-1 (MCP-1) were elevated, as were levels of antiinflammatory cytokines TGF- $\beta 1$, TGF- $\beta 2$, and TGF- $\beta 3$ but not IL-10. Yilmaz et al. compared the use of a scalpel, electrocautery and ultrasonic dissection during mastectomy [20]. Interesting, electrocautery induced significantly higher levels of cytokines than scalpel and ultrasonic dissection. The authors measured IL-6 and TNF in drain fluid within 24 $h$ after surgery. Somewhat elevated IL-6 and TNF levels were observed. The latter is a bit puzzling and represents a discrepancy with our results. TNF stimulates the acute-phase reaction and pro-inflammatory cytokines IL-6 and IL-8. However, the present observation of high concentrations of IL-6, the most important mediators of fever and the acute- phase response, and IL-8, the major mediator of the inflammatory response, clearly indicate that seroma formation has an inflammatory component. We only observed elevations in early pro-inflammatory cytokines and no elevation in anti-inflammatory cytokines. The latter is not seen even at the end of seroma production. Whether the elevated cytokines is a causal effect is unclear. In contrast to the effect of 5-fluorouracil in the rat model, a single prophylactic intravenous dose of steroid preoperatively at mastectomy did not diminish seroma formation in humans [21]. The lack of immune suppression of the steroid could be because no sustained release formula was used or because the dose was too small. In contrast, Taghizadeh et al. demonstrated a significant reduction of seroma formation when steroid was administered into the cavity at the site of seroma puncture [22]. Rogliani et al. demonstrated reduced seroma production after steroid injections in the extended latissimus dorsi donor site after reconstructive surgery [23].

\section{CONCLUSION}

In conclusion, seroma formation after mastectomy most likely is a pro-inflammatory process, as indicated by the very high levels of IL-6 and IL-8. However, these levels do not predict the cause of seroma production. Our findings and recent reports indicate that inhibiting inflammation might be a plausible preventive treatment.

\section{ACKNOWLEDGEMENTS}

The authors express their gratitude to Mrs. Dorthe Kroghave Toftdahl Pedersen for excellent technical assistance. 

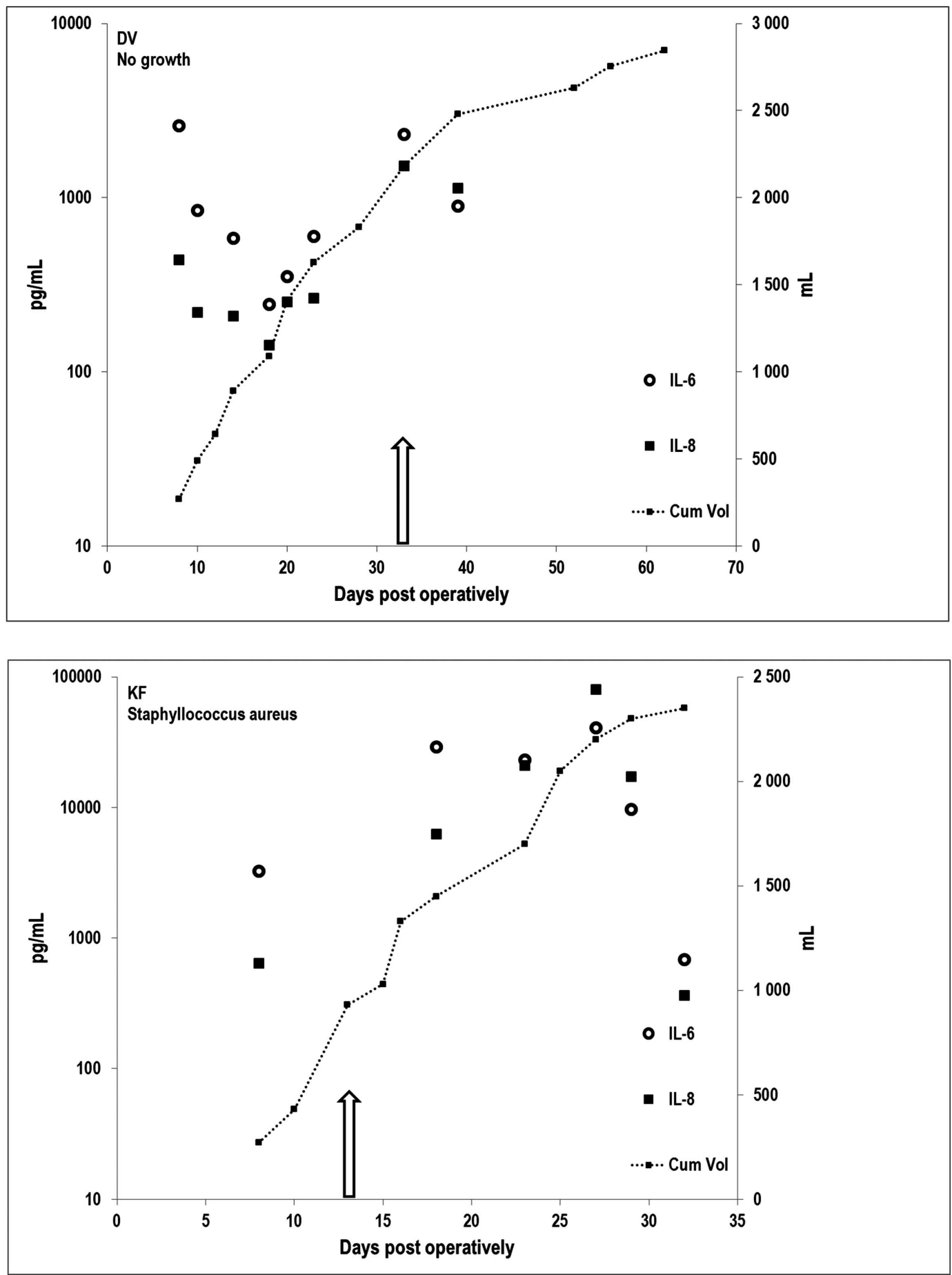

Fig. (3). Timeline of seroma fluid production from two patients with clinical infection and with (KF) and without (DV) positive bacterial culture. In addition to interleukin- 6 (IL-6) and interleukin-8 (IL-8) concentrations is the cumulative seroma volume (Cum Vol) in mL (secondary axis) is shown. The arrows indicate the time of symptoms of clinical infection.

\section{CONFICT OF INTEREST}

The authors confirm that this article content has no conflicts of interest.

\section{ABBREVIATIONS}

IL-10 = Interleukin-10

IL-12 = Interleukin-12p70
IL-1 = Interleukin-1 $\beta$

IL-6 = Interleukin-6

IL-8 = Interleukin-8

MCP-1 = Monocyte chemotactic protein-1

MO = Local excision in mammary tissue only

$\mathrm{PM}=$ Partial mastectomy 
$\mathrm{RM}=$ Radical mastectomy

TGF- $\beta=$ Transforming growth factor beta

TIMP-1 = Tissue inhibitor of metalloproteinase 1

$\mathrm{TNF}=$ Tumor necrosis factor alpha

\section{REFERENCES}

[1] Kuroi K, Shimozuma K, Taguchi T, et al. Pathophysiology of seroma in breast cancer. Breast Cancer 2005; 12: 288-93.

[2] Shamley DR, Barker K, Simonite V, Beardshaw A. Delayed versus immediate exercises following surgery for breast cancer: a systematic review. Breast Cancer Res Treat 2005; 90: 263-71.

[3] Kuroi K, Shimozuma K, Taguchi T, et al. Evidence-based risk factors for seroma formation in breast surgery. Jpn J Clin Oncol 2006; 36: 197-206.

[4] Gardner A, Pass HA, Prance S. Techniques in the prevention and management of breast seroma: An evaluation of current practice. Women's Oncol Rev 2005; 5: 135-43.

[5] Montalto E, Mangraviti S, Costa G, et al. Seroma fluid subsequent to axillary lymph node dissection for breast cancer derives from an accumulation of afferent lymph. Immunol Lett 2010; 131: 67-72.

[6] Watt-Boolsen S, Nielsen VB, Jensen J, Bak S. Postmastectomy seroma. A study of the nature and origin of seroma after mastectomy. Dan Med Bull 1989; 36: 487-9.

[7] McCaul JA, Aslaam A, Spooner RJ, Louden I, Cavanagh T, Purushotham AD. Aetiology of seroma formation in patients undergoing surgery for breast cancer. Breast 2000; 9: 144-8.

[8] Speyer CL, Ward PA. Role of endothelial chemokines and their receptors during inflammation. J Invest Surg 2011; 24: 18-27.

[9] Wong HL, Pfeiffer RM, Fears TR, Vermeulen R, Ji S, Rabkin CS. Reproducibility and correlations of multiplex cytokine levels in asymptomatic persons. Cancer Epidemiol Biomarkers Prev 2008; 17: 3450-6.

[10] Kader HA, Truong PT, Pai R, et al. When is CT-based postoperative seroma most useful to plan partial breast radiotherapy? Evaluation of clinical factors affecting seroma volume and clarity. Int J Radiat Oncol Biol Phys 2008; 72: 1064-9.

[11] Bierman HR, Byron RL, Kelly KH, et al. The characteristics of thoracic duct lymph in man. J Clin Invest 1953; 32: 637-49.
[12] Merrigan BA, Winter DC, O'Sullivan GC. Chylothorax. Br J Surg 1997; 84: 15-20.

[13] Al-Gaithy ZK, Ayuob NN. Vascular and cellular events in postmastectomy seroma: an immunohistochemical study. Cell Immunol 2012; 272: 130-6

[14] Semaeva E, Tenstad O, Skavland J, et al. Access to the spleen microenvironment through lymph shows local cytokine production, increased cell flux, and altered signaling of immune cells during lipopolysaccharide-induced acute inflammation. J Immunol 2010; 184: 4547-56.

[15] Olszewski WL, Pazdur J, Kubasiewicz E, Zaleska M, Cooke CJ, Miller NE. Lymph draining from foot joints in rheumatoid arthritis provides insight into local cytokine and chemokine production and transport to lymph nodes. Arthritis Rheum 2001; 44: 541-9.

[16] Kocdor MA, Kilic YD, Kocdor H, et al. Effects of locally applied 5 -fluorouracil on the prevention of postmastectomy seromas in a rat model. Eur Surg Res 2008; 40: 256-62.

[17] Baker EA, Kumar S, Melling AC, Whetter D, Leaper DJ. Temporal and quantitative profiles of growth factors and metalloproteinases in acute wound fluid after mastectomy. Wound Repair Regen 2008; 16: $95-101$.

[18] Loo WT, Sasano H, Chow LW. Pro-inflammatory cytokine, matrix metalloproteinases and TIMP-1 are involved in wound healing after mastectomy in invasive breast cancer patients. Biomed Pharmacother 2007; 61: 548-52.

[19] Robin BN, Chaput CD, Zeitouni S, Rahm MD, Zerris VA, Sampson HW. Cytokine-mediated inflammatory reaction following posterior cervical decompression and fusion associated with recombinant human bone morphogenetic protein-2: a case study. Spine (Phila Pa 1976 ) 2010; 35: E1350-4

[20] Yilmaz KB, Dogan L, Nalbant H, et al. Comparing scalpel, electrocautery and ultrasonic dissector effects: the impact on wound complications and pro-inflammatory cytokine levels in wound fluid from mastectomy patients. J Breast Cancer 2011; 14: 58-63.

[21] Okholm M, Axelsson CK. No effect of steroids on seroma formation after mastectomy. Dan Med Bull 2011; 58: A4241.

[22] Taghizadeh R, Shoaib T, Hart AM, Weiler-Mithoff EM. Triamcinolone reduces seroma re-accumulation in the extended latissimus dorsi donor site. J Plast Reconstr Aesthet Surg 2008; 61: 636-42.

[23] Rogliani M, Gentile P, Cervelli V. Seroma treatment after dermolipectomy. Ann Chir Plast Esthet 2008; 53: 534-6.

Received: May 21, 2012

Revised: July 17, 2012

Accepted: July 23, 2012

(C) Szecsi et al.; Licensee Bentham Open.

This is an open access article licensed under the terms of the Creative Commons Attribution Non-Commercial License (http://creativecommons.org/licenses/by-nc/ $3.0 /$ ) which permits unrestricted, non-commercial use, distribution and reproduction in any medium, provided the work is properly cited. 